$\mathbb{T}$ periodica polytechnica

Chemical Engineering

58/1(2014)1-6

doi:10.3311/PPch.7048

http://www.periodicapolytechnica.org/ch

Creative Commons Attribution (1)

RESEARCH ARTICLE

\section{Determination of sorbitol in the presence of high amount of mannitol from biological samples}

\author{
Bálint Tomasskovics / Viola Horváth / József Balla / Ferenc Örsi / András Szarka
}

RECEIVED 24 SePtember 2013; ACCePted 17 October 2013

\begin{abstract}
Preparation of intact mitochondria requires the use of an osmoticum in high concentration that preserves the mitochondrial structure and prevents physical swelling and rupture of membranes. For this purpose mannitol is widely accepted as a component of the homogenization medium. The formation of sorbitol in plant mitochondria can be an important element of plant response to salinity and drought. The large difference in the concentration of possibly formed sorbitol and mannitol of the homogenisation medium makes the determination of sorbitol difficult. Gas-chromatography with flame ionization detection (GC-FID), gas-chromatography coupled to quadrupole mass spectrometry (GC-QPMS) and liquid chromatography/tandem mass spectrometry (LC/MS-MS) using hydrophilic interaction chromatography (HILIC) were tested to quantify this highly polar sugar alcohol: Although all three methods offered satisfactory results, the HPLC/MS-MS technique proved to be the best.
\end{abstract}

\section{Keywords}

plant mitochondria $\cdot$ sorbitol determination · liquid chromatography/tandem mass

\section{Acknowledgement}

This work was financially supported by National Scientific Research Fund grants (OTKA 77826, 105416) and by the New Széchenyi Development Plan (TÁMOP-4.2.1/B-09/1/KMR-2010-0002).

\section{Bálint Tomasskovics}

Ferenc Örsi

András Szarka

Department of Applied Biotechnology and Food Science,

Laboratory of Biochemistry and Molecular Biology,

Budapest University of Technology and Economics,

Szent Gellért tér 4., H-1111 Budapest, Hungary

e-mail: szarka@mail.bme.hu

Viola Horváth

Department of Inorganic and Analytical Chemistry,

Budapest University of Technology and Economics,

Szent Gellért tér 4., H-1111 Budapest, Hungary

József Balla

B\&B Analytics Ltd., Terasz u. 60., H-2030 Érd, Hungary

\section{Introduction}

Invertase activity and the corresponding transport of fructose, glucose and sucrose were described in mitochondria isolated from Jerusalem artichoke tubers [16]. Following this observation the enzyme was found in mitochondria from other plant species suggesting that it is a general feature of plant cells. The prokaryotic origin of mitochondria gave an idea on the physiological role of this carbohydrate conversion system. A sucrose-glucose/ fructosesorbitol pathway has been described, as the central osmoregulation machinery, in the prokaryotic Zymomonas mobilis [9]. This bacterial mechanism provides special importance to the observations that several plant species accumulate different sugar alcohols under drought and salt stress $[3,5,13,15]$ and sorbitol can be one of the key components of the osmotic stress adaptation mechanism [12]. In order to verify this hypothesis and gain insight into the mitochondrial production of sorbitol, an appropriate analysis method had to be developed.

To prepare intact mitochondria from different (plant) sources, a homogenization medium should be used which consists of 0.3-0.4 $\mathrm{M}$ of an osmoticum. The osmoticum preserves the mitochondrial structure and prevents physical swelling and rupture of membranes. Sucrose and mannitol are generally used osmolytes in mitochondrial research [7,20]. On one hand the application of sucrose as osmoprotectant in the investigation of mitochondrial sorbitol formation is not possible, due to the mitochondrial invertase activity which cleaves sucrose into glucose and fructose, therefore it would interfere with the observation of sorbitol formation (from glucose and fructose). On the other hand mannitol and sorbitol are epimers, with only one stereogenic centre difference in their configuration, they lack chromophores or fluorophores. Thus the separation and detection of these molecules are difficult. Since the level of intactness of isolated mitochondria was not satisfactory when xylitol was applied in the preparation of animal and plant mitochondria [18] it cannot be used as an osmolyte in the preparation of mitochondria.

Gas-chromatgraphy (GC) with flame ionization or mass spectrometry detection are widely applied techniques for sugar 
alcohol determination $[6,10,11])$. However carbohydrates - due to their high polarity, hydrophilicity and low volatility - should be converted into volatile and stable derivatives prior to GC injection. Silylation is used widely as a derivatization procedure since silyl derivatives are more volatile, less polar, and more stable than their parent compounds [2]. To avoid the time-consuming derivatization step liquid-chromatography can also be a suitable choice for sugar alcohol determination. High-performance anion-exchange chromatography (HPAEC) coupled to pulsed amperometric detection (PAD) or hydrophilic interaction liquid chromatography (HILIC) coupled to electrospray ionisation tandem mass spectrometry (ESI-MS-MS) are powerful tools for the analysis of these highly polar compounds [8,17].

Sorbitol and mannitol at millimolar concentrations can be efficiently separated with these techniques. Since isolated mitochondrial fraction contains only a limited amount of mitochondrial proteome, only limited sorbitol formation can be expected. Hence in the reaction medium a small amount $(0.1-1 \mathrm{mM})$ of sorbitol should be measured in the presence of a large amount of mannitol (0.4 M). Due to these reasons, we aimed at the development of a suitable chromatographic method for the determination of sorbitol in the presence of high amount of mannitol. Three different techniques were compared: gas-chromatography with flame ionization detection (GC-FID), gas-chromatography coupled to quadrupole mass spectrometry (GC-QPMS), and hydrophilic interaction liquid chromatography coupled with electrospray ionisation and tandem mass spectrometry.

\section{Materials and methods Materials}

Ethylenediaminetetraacetic acid (EDTA), Trishydroxymethylaminomethane (Tris), 4-morpholinepropanesulfonic acid (MOPS), mannitol, sorbitol, xilitol, bovine serum albumin (BSA) were obtained from Sigma. Hexamethyldisilazane (HMDS) - trimethylchlorosilane (TMCS) - pyridine mixture was obtained from Supelco. Percoll was purchased from Applied Biosystems. ${ }^{13} \mathrm{C}_{6}$ labeled glucose, fructose, sorbitol were purchased from Cambridge Isotope Laboratories. All other chemicals were of analytical grade.

\section{Preparation of mitochondria}

Jerusalem artichoke (Helianthus tuberosus L.) tubers were purchased from the local market. Mitochondria were freshly isolated from the tubers as described by Szarka et al. [16].

\section{Sample preparation}

$100-250 \mu$ freshly purified mitochondria isolated from Jerusalem artichoke were used in the experiments. Mitochondria (approx. $1 \mathrm{mg} / \mathrm{ml}$ ) were incubated in a buffer containing $300 \mathrm{mM}$ mannitol, $10 \mathrm{mM}$ MOPS, $\mathrm{pH} 7.4$ at room temperature $\left(22-25^{\circ} \mathrm{C}\right)$. Incubations were initiated by the addition of $100 \mathrm{mM}$ glucose and fructose. After $2 \mathrm{~h}$ of incubation the reactions were terminated by the addition of 0.05 volume of Carrez I reagent (30\% (w/v) zinc acetate). The excess of Carrez I reagent was eliminated by the addition of the same volume of Carrez II reagent (15\% (w/v) ferrocyanide). Samples were centrifuged at $18,000 \mathrm{~g}$ for $10 \mathrm{~min}$ at $4^{\circ} \mathrm{C}$. The volume of the supernatant was determined by micropipette, 250 - $500 \mu \mathrm{l} 80 \mathrm{v} / \mathrm{v} \%$ ethanol/water was added to the samples, mixed well for $1 \mathrm{~h}$ and centrifugated at $18,000 \mathrm{~g}$ for $5 \mathrm{~min}$ at $4^{\circ} \mathrm{C}$. The extracted aliquots $(100 \mu \mathrm{l})$ were transferred into $1.5-\mathrm{mL}$ Eppendorf tubes and the solvents were evaporated completely using a vacuum concentrator (Speed Vac Plus SC11A).

Standard stock solutions of sugars, sugar alcohols were also prepared at different concentrations (1M glucose, fructose, mannitol; 100mM sorbitol) in water. For GC/GC-MS analysis after appropriate dilution they were evaporated and dissolved in the derivatization mix, for LC-MS-MS analysis they were diluted in the mobile phase. Procedural blanks were analysed with every run.

\section{Derivatization}

Silylation reactions were carried out with the following derivatization mixture: HMDS+TMCS+Pyridine, 3:1:9 (Sylon $^{\mathrm{TM}}$ HTP, Supelco). 100-200 $\mu$ of silylation mixture was added to the evaporated samples. The mixture was vortexed for $10 \mathrm{~min}$ utes and kept overnight to form the trimethylsilyl products. The verification of derivatization of standard compounds at different concentrations was monitored by thin layer chromatography as described by Waldi et al. [19]. Derivatized extracts were evaporated to dryness and dissolved in 100-200 $\mu \mathrm{l}$ of hexane for analysis. Prior to analysis, xylitol-TMS as internal standard was added to the samples.

\section{Gas-chromatography - flame ionization detection (GC-FID)}

Gas chromatographic analyses were carried out on a Fisons Instruments gas-chromatograph equipped with a flame ionization detector (GC 8060 CB). Trimethyl-silyl (TMS) derivatives were separated on a nonpolar fused silica capillary column DB-1 (30 m x 0.25 mm id. x $1 \mu \mathrm{m}$ film; Agilent) helium was used as carrier gas. The injection temperature was $270^{\circ} \mathrm{C}$ the detector temperature was $250^{\circ} \mathrm{C}$. The oven temperature program was the following: $100^{\circ} \mathrm{C}$ initial temperature was held for 2 min then temperature increased to $300^{\circ} \mathrm{C}$ by $5^{\circ} \mathrm{C} / \mathrm{min}$. This was followed by an isothermal hold at $300^{\circ} \mathrm{C}$ for $10 \mathrm{~min}$. The injection volume was $1 \mu \mathrm{l}$. Polyols were identified by comparison of retention times of peaks of silylated standard compounds. Quantification of each compound was performed using the internal standard calculation method.

\section{Gas-chromatography - mass spectrometry (GC-MS)}

Gas chromatographic - mass spectrometric analyses were carried out on a Shimadzu GC-MS system (GCMS - QP2010). For the measurements a ZB-5 capillary column $(30 \mathrm{~m} \times 0.25 \mathrm{~mm}$ 
I.D., film thickness of $0.25 \mu \mathrm{m}$, Zebron) was used. The carrier gas was helium at a constant flow rate of $1 \mathrm{~mL} / \mathrm{min}$. The injector and MS source temperatures were $280^{\circ} \mathrm{C}$ and $260^{\circ} \mathrm{C}$ respectively. The column temperature program was the same as in the GC-FID measurements. The MS was operated in electron impact mode, the ionization energy was $70 \mathrm{eV}$. Scan range was from 50 to 350 Da. Samples were analyzed in split mode the split ratio was $1: 100.1 \mu \mathrm{l}$ of the sample was injected into the GC-MS system. Compound identification was performed by comparison of retention times of peaks and mass spectra of authentic standards, and the mass spectral library of the GC-MS data system. Compounds were quantified using extracted ion chromatogram (m/z 319) peak area, and the internal standard calculation method.

\section{LC/MS-MS}

LC/MS-MS analyses were carried out on a Perkin Elmer HPLC system (Series 200) coupled to an electrospray ionisation triple quad mass spectrometer (Perkin Elmer Sciex API 365). Chromatographic separation was performed on a zwitterionic ZIC-pHILIC stationary phase $(150 \times 2.1 \mathrm{~mm}, 5 \mu \mathrm{m}$; SeQuant, Merck). The flow rate of the isocratic elution was $100 \mu \mathrm{L} / \mathrm{min}$, the sample injection volume was $5 \mu \mathrm{L}$, the HILIC column was used at ambient temperature $\left(25^{\circ} \mathrm{C}\right)$ and sample run time was 40 min. Mobile phase composed of $80 \%$ acetonitrile- 5\% methanol and 15\% $20 \mathrm{mM}$ ammonium acetate buffer ( $\mathrm{pH}$ 9).

Standards of ${ }^{13} \mathrm{C}_{6}$ labelled fructose, glucose, sorbitol and ${ }^{12} \mathrm{C}_{6}$ mannitol were used for identification and quantification of peaks. Negative ion mode electrospray ionization (ESI) and multiple reaction monitoring mode (MRM) were employed for all analytes. Optimum parameters were determined for each standard compound using their $10 \mu \mathrm{g} / \mathrm{mL}$ solution in methanol by direct infusion with a syringe pump. Mass spectra were acquired over the scan range $\mathrm{m} / \mathrm{z} 50$ to 500 of each standard compounds. Deprotonated $[\mathrm{M}-\mathrm{H}]^{-}$ ions were selected as precursor ions, product ions after collision induced fragmentation were selected for compound determination. Table 1 shows the MRM transitions used for the different analytes. Data were processed using Analyst 1.4.2 software.

\section{Results and discussion}

Appropriate separation of mannitol and sorbitol standards could be reached at millimolar concentrations by GC-FID using a nonpolar fused silica capillary column (Fig. 1a). Retention times for mannitol and sorbitol were 25.50 and 25.63 min respectively. A significant peak widening could be observed analyzing the mitochondrial samples due to the high mannitol concentration therefore sorbitol could not be determined reliably. The dilution of the samples resulted in the successful separation and determination, but several unknown background peaks could be detected at the expected retention time of sorbitol (Fig. 1b). To avoid incorrect recognition of the desired peak, the use of the time consuming standard addition method was necessary.
Tab. 1. Selected precursor ion and product ion masses for compound determination by HPLC-MS/MS

\begin{tabular}{ccc}
\hline Compound name & $\begin{array}{c}\text { Precursor ion mass } \\
(\mathrm{m} / \mathrm{z})\end{array}$ & $\begin{array}{c}\text { Product ion masses } \\
(\mathrm{m} / \mathrm{z})\end{array}$ \\
\hline glucose ${ }^{13} \mathrm{C}_{6}$ & 184.6 & $61.0 ; 91.9$ \\
fructose ${ }^{13} \mathrm{C}_{6}$ & 184.6 & $61.0 ; 91.9$ \\
sorbitol ${ }^{13} \mathrm{C}_{6}$ & 186.6 & $61.0 ; 91.9$ \\
mannitol ${ }^{12} \mathrm{C}_{6}$ & 186.6 & $89.0 ; 91.9$ \\
xylitol ${ }^{12} \mathrm{C}_{6}$ & 150.6 & $89.0 ; 70.9$ \\
\hline
\end{tabular}

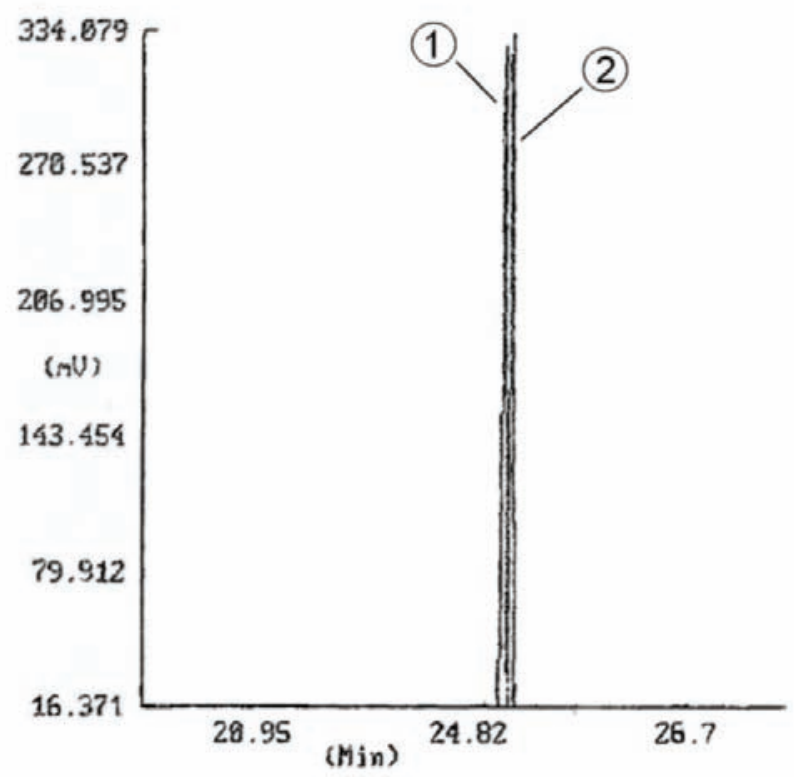

(a)

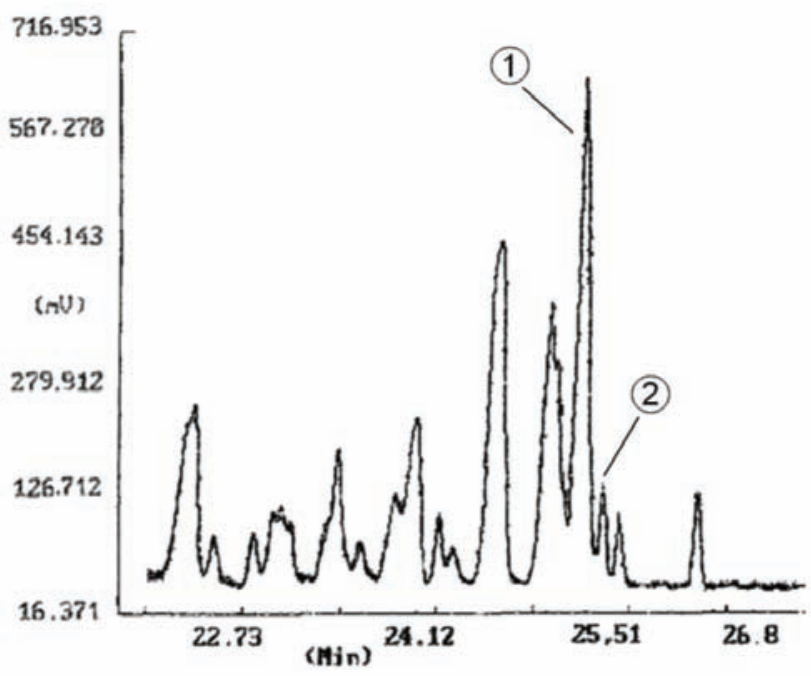

(b)

Fig. 1. GC-FID chromatogram of (a) silylated 1mM mannitol and sorbitol standards (b) silylated Jerusalem artichoke mitochondrial sample. Identified peaks: (1) mannitol (2) sorbitol. GC conditions: DB-1 column (30 m x 0.25 mm id. $\mathrm{x} 1 \mu \mathrm{m}$ film), $1 \mathrm{~mL} / \mathrm{min}$ flow, $1 \mu \mathrm{L}$ injection. 
Gas-chromatography coupled with mass spectrometry provided excellent qualitative analysis due to the capability of structural identification of the compounds. Despite of the same MS fragmentation pattern observed in the case of mannitol and sorbitol, the capillary column provided the sufficient separation of these sugar alcohols at millimolar concentration range (Fig. 2a). Retention times for mannitol and sorbitol were 24.14 and 24.31 min respectively. Furthermore sorbitol could be measured at millimolar concentration, in the presence of high amount of mannitol (0.4M) after appropriate dilution of the mitochondrial samples (Fig. 2b).

Unfortunately the reproducibility of the derivatized mitochondrial samples was not sufficient in some cases. Mitochondrial samples derivatized parallel had different colours and morphology after the evaporation. No similar problems could be observed in the case of the standards. The differences observed between mitochondrial samples could not be avoided by the application of different amount of derivatization mixtures. This unpredictable behaviour of mitochondrial samples made the analysis difficult by this method.

The disturbing effects of the mitochondrial background could be avoided by the determination of the pure sugar alcohol production due to the putative mitochondrial aldose reductase activity. The application of ${ }^{13} \mathrm{C}$ labelled substrates $\left({ }^{13} \mathrm{C}_{6}\right.$ glucose and fructose) and consequently the formation of ${ }^{13} \mathrm{C}$ labelled products $\left({ }^{13} \mathrm{C}_{6}\right.$ sorbitol) by mitochondria offers the advantage that these compounds can be selectively measured by mass spectrometry, due to the mass difference of the labelled compounds.

HPLC-MS-MS technique combined with hydrophilic interaction liquid chromatography also offers an appropriate solution to eliminate the time, sample consuming and uncertain derivatization step. Although traditional silica-based columns are not stable at high $\mathrm{pH}$, the ZIC-pHILIC polymeric column gives the possibility to apply basic ( $\mathrm{pH}$ 9) mobile phase for the separation. Therefore sugars and sugar alcohols can be separated and detected in negative ion mode, as deprotonated $[\mathrm{M}-\mathrm{H}]^{-}$(negatively charged compounds). The MRM mode detects only product ions from the selected precursor ions, therefore chemical background and other components of reaction media were absent from the mass spectrum. The investigated highly polar analytes could not be dissolved in the acetonitril-water mixture that was initially used as mobile phase. However the addition of methanol to the mobile phase solved this problem. The applied column and mobile phase provided the separation of sorbitol and mannitol at the

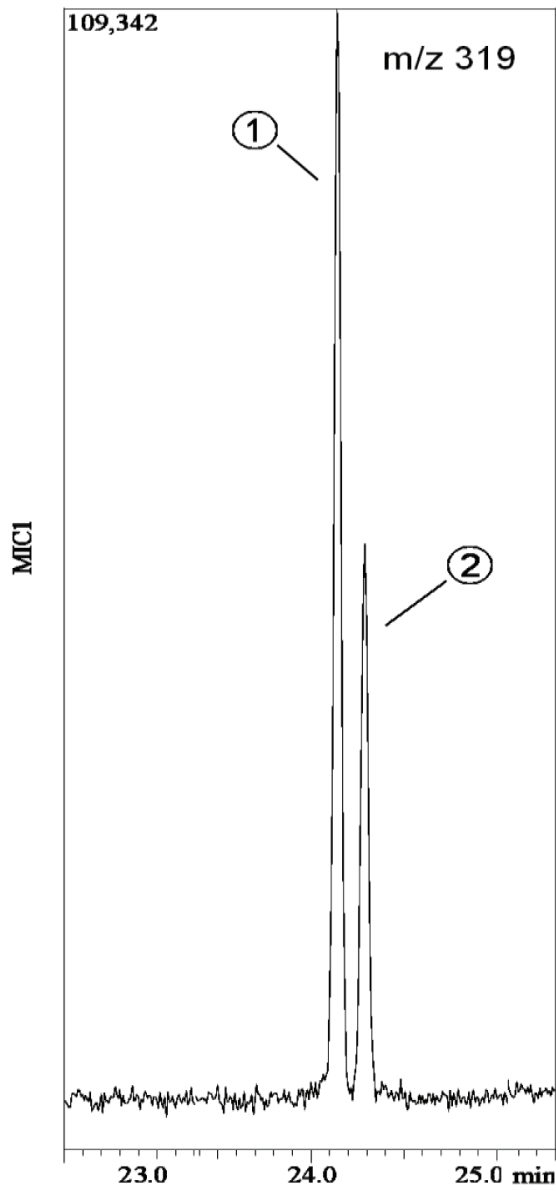

(a)

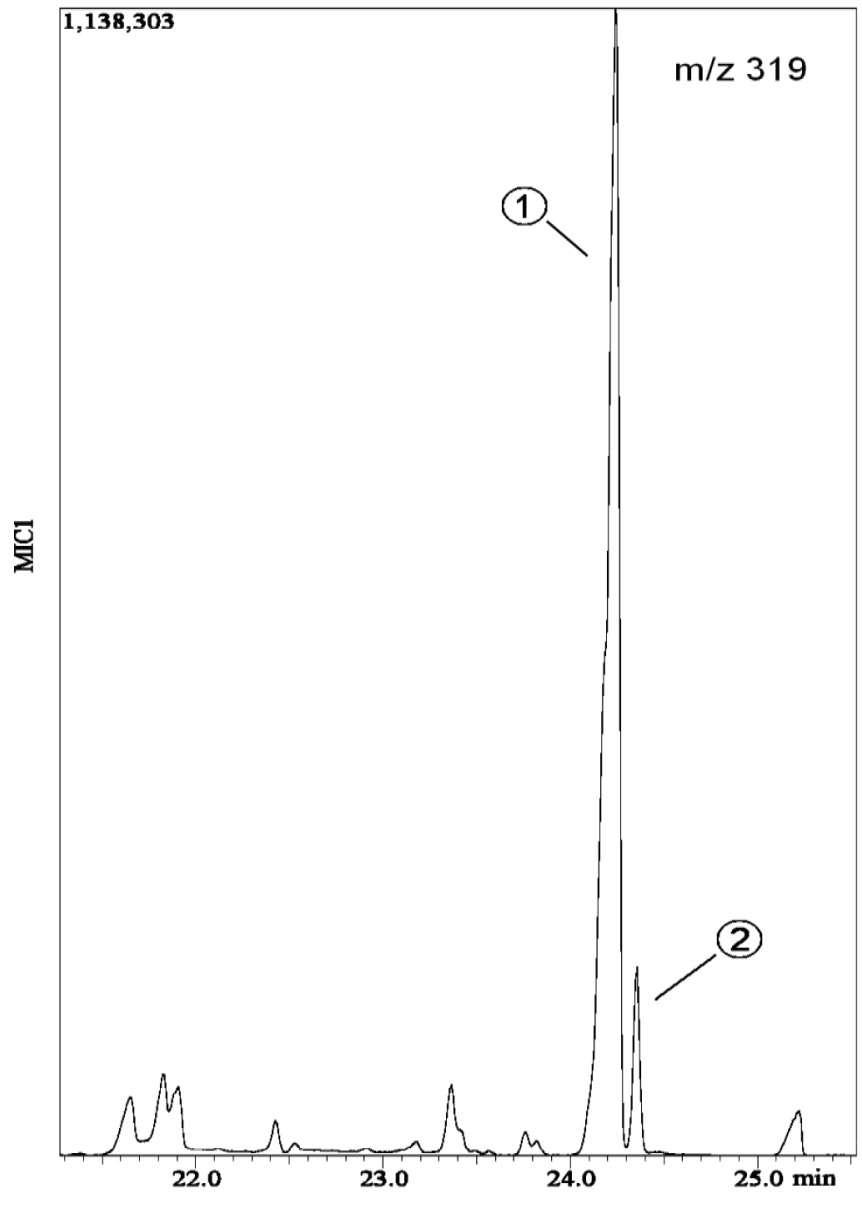

(b)

Fig. 2. GC-MS extracted ion chromatograms of (a) silylated $1 \mathrm{mM}$ mannitol and 0,5 $\mathrm{mM}$ sorbitol standards (b) silylated Jerusalem artichoke mitochondrial sample. Identified peaks: (1) mannitol (2) sorbitol. GC conditions: ZB-5 column $(30 \mathrm{~m} \times 0.25 \mathrm{~mm}$ i.d., $0.25 \mu \mathrm{m}$ film, $1 \mathrm{~mL} / \mathrm{min}$ flow, $1 \mu \mathrm{L}$ injection. 
level of millimolar concentrations (Fig. 3a). Retention times for sorbitol and mannitol were 20.97 and 22.40 min respectively. The use of ${ }^{13} \mathrm{C}$ labelled substrates $\left({ }^{13} \mathrm{C}_{6}\right.$ glucose, fructose) and ${ }^{12} \mathrm{C}_{6}$ mannitol as osmoticum allowed us to measure sorbitol production selectively. Low amount of ${ }^{13} \mathrm{C}_{6}$ sorbitol could be determined in the presence of high amount of mannitol in mitochondrial samples (Fig. 3b spiked mitochondrial sample).

Finally, our goals could be reached by the above detailed HPLC-MS-MS method. It is suitable to determine such a low amount of sorbitol (0.1-1 mM) in the presence of high amount of mannitol (0.4 M) from mitochondrial samples. Hence the assessment of sugar alcohol production of plant mitochondria can be achieved.

\section{Conclusions}

Although sorbitol could be determined selectively and in low concentration by all three applied methods (GC-FID, GC-MS, HPLC-MS-MS), the requirements of the biological sample (low amount of sorbitol in the presence of high amount of mannitol in a complex, biological matrix) could only be fulfilled by the newly developed HPLC-MS-MS method.
Our HILIC method offers a much better separation for these highly polar and closely related sugar alcohols than similar methods reported in the literature [1] therefore ion suppression in mitochondrial samples is less problematic.

Although the LC-MS/MS technique requires expensive instrumentation, and costly ${ }^{13} \mathrm{C}$ labelled standards it provides sensitive and reliable qualitative and quantitative analysis of complex matrices using simplified sample preparation. The combination of ${ }^{13} \mathrm{C}$ labelled standards and HILIC-ESI-MS-MS allowed us the accurate assessment of sugar alcohol production of mitochondria derived samples and could easily be used with other plant species.

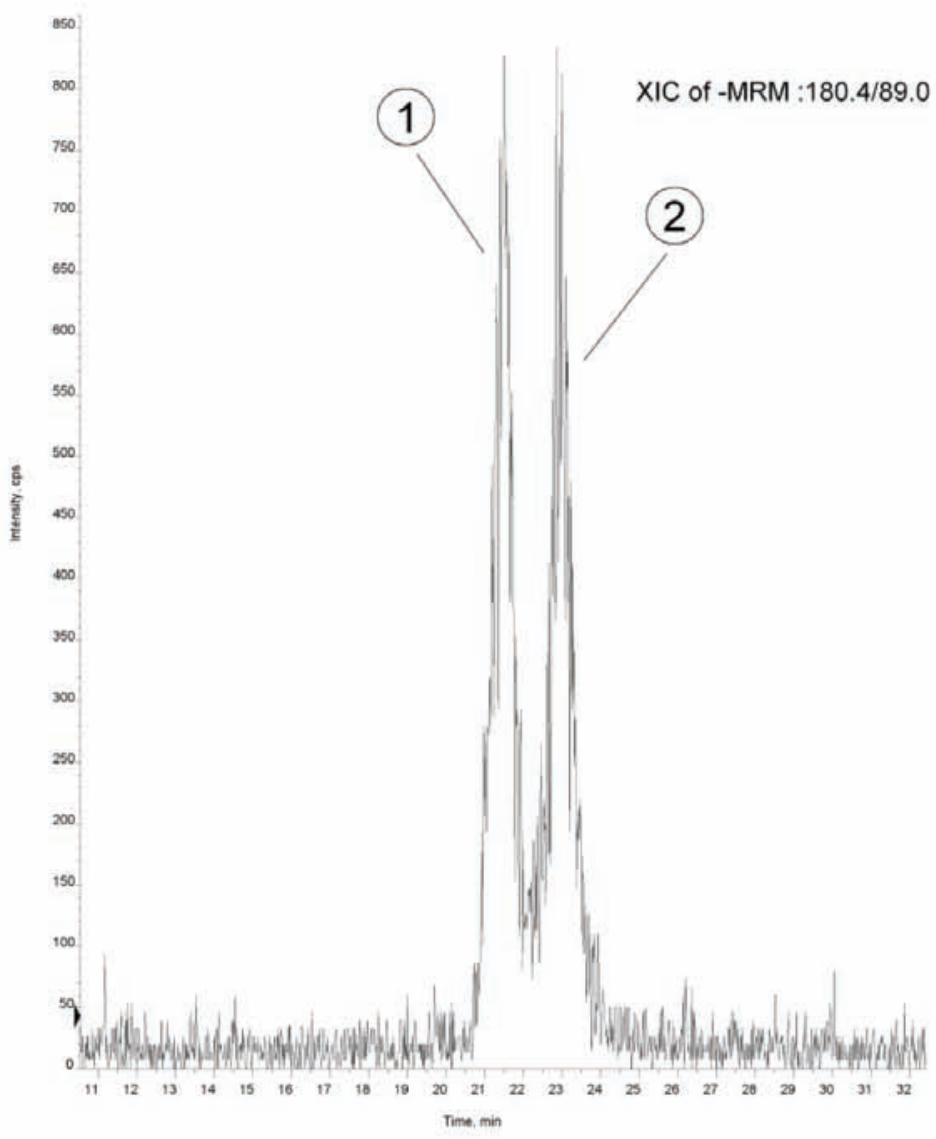

(a)

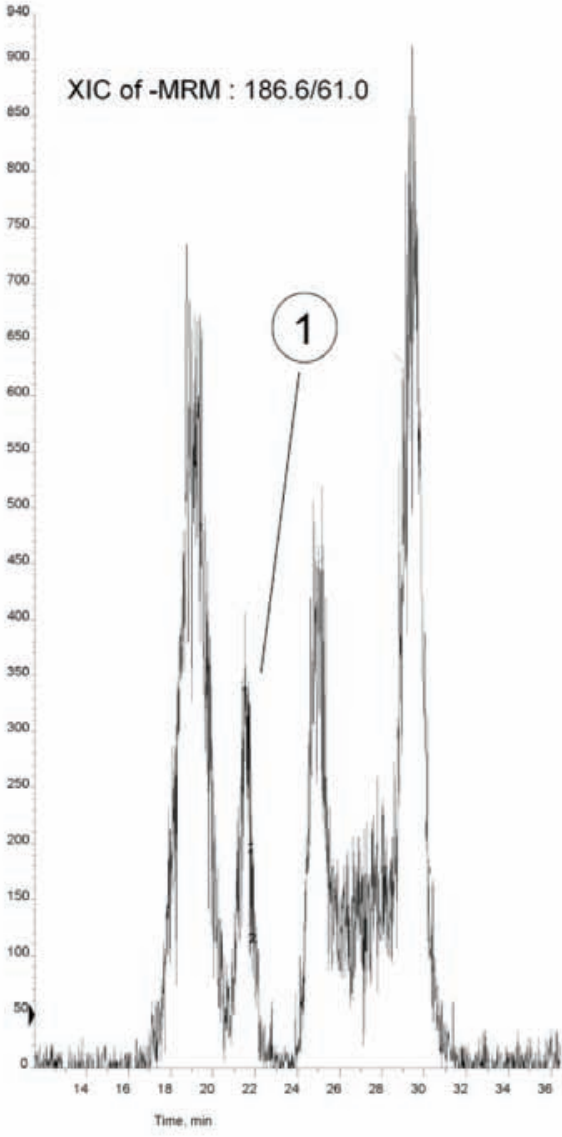

(b)

Fig. 3. Extracted ion chromatograms obtained by HILIC-ESI-MS/MS: (a) $100 \mu \mathrm{M}{ }^{12} \mathrm{C}_{6}$ mannitol and sorbitol standards (b) Jerusalem artichoke mitochondrial sample spiked with $100 \mu \mathrm{M}^{13} \mathrm{C}_{6}$ sorbitol. Identified peaks: (1) sorbitol (2) mannitol. HPLC-MS/MS conditions: ZIC-pHILIC column (150 x 2.1mm, 5 $\mu \mathrm{m}$ ), $200 \mu \mathrm{L} / \mathrm{min}, 5 \mu \mathrm{L}$ injection; negative ion $[\mathrm{M}-\mathrm{H}]^{-}$ESI-MS/MS 


\section{References}

1 Antonio C., Larson T., Gilday A., Graham I., Bergström E., Thomas-Oates J., Hydrophilic interaction chromatography/electrospray mass spectrometry analysis of carbohydrate-related metabolites from Arabidopsis thaliana leaf tissue. Rapid Communications in Mass Spectrometry, 22(9), 1399-1407 (2008).

DOI: $10.1002 / \mathrm{rcm} .3519$

2 Blau K., Halket J., Handbook of Derivatives for Chromatography (2nd ed.). John Wiley \& Sons, New York (1993).

3 Everard J. D., Gucci R., Kann S. C., Flore J. A., Loescher W. $\mathrm{H}$., Gas exchange and carbon partitioning in the leaves of celery (Apium graveolens L.) at various levels of root zone salinity. Plant Physiology, 106(1), 281-292 (1994).

DOI: 10.1104/pp.106.1.281

4 Harvey D. J., Derivatization of carbohydrates for analysis by chromatography; electrophoresis and mass spectrometry. Journal of Chromatography B, 879(17-18), 1196-1225 ( 2011). DOI: $10.1016 / j . j$ jchromb.2010.11.010

5 Hu L., Lu H., Liu Q., Chen X., Jiang X., Overexpression of mtlD gene in transgenic Populus tomentosa improves salt tolerance through accumulation of mannitol. Tree Physiology, 25(10), 12731281 (2005) DOI: $10.1093 /$ treephys/25.10.1273

6 Kostál V., Zahradnícková H., Simek P., Zelený J., Multiple component system of sugars and polyols in the overwintering spruce bark beetle, Ips typographus. Journal of Insect Physiology, 53(6), 580-586 (2007).

DOI: 10.1016/j.jinsphys.2007.02.009

7 Kruft V., Eubel H., Jänsch L., Werhahn W., Braun H.-P., Proteomic approach to identify novel mitochondrial proteins in Arabidopsis. Plant Physiology, 127(4), 1694-1710 (2001).

DOI: $10.1104 / \mathrm{pp} .010474$

8 Lee Y. C., Carbohydrate analyses with high-performance anionexchange chromatography. Journal of Chromatography A, 720(1-2), 137-149 (1996).

DOI: 10.1016/0021-9673(95)00222-7

9 Loos H., Krämer R., Sahm H., Sprenger G. A., Sorbitol promotes growth of Zymomonas mobilis in environments with high concentrations of sugar: evidence for a physiological function of glucose-fructose oxidoreductase in osmoprotection. Journal of Bacteriology, 176(24), 7688-7693 (1994).

10 Marsilio V., Campestre C., Lanza B., De Angelis M., Sugar and polyol compositions of some European olive fruit varieties (Olea europaea L.) suitable for table olive purposes. Food Chemistry, 72(4), 485-490 (2001). DOI: $10.1016 / \mathrm{S} 0308-8146(00) 00268-5$

11 Medeiros P. M., Simoneit B. R. T., Analysis of sugars in environmental samples by gas chromatography-mass spectrometry. Journal of Chromatography A, 1141(2), 271-278 (2007).

DOI: $10.1016 / j . c h r o m a .2006 .12 .017$
12 Pommerrenig B., Papini-Terzi F. S., Sauer N., Differential Regulation of Sorbitol and Sucrose Loading into the Phloem of Plantago major in Response to Salt Stress. Plant Physiology, 144(2), 1029-1038 (2007). DOI: 10.1104/pp.106.089151

13 Rejšková A., Patková L., Stodůlková E., Lipavská H., The effect of abiotic stresses on carbohydrate status of olive shoots (Olea europaea L.) under in vitro conditions. Journal of Plant Physiology, 164(2), 174-184 (2007). DOI: 10.1016/j.jplph.2005.09.011

14 Ruiz-Matute A. I., Hernández-Hernández O., RodríguezSánchez F., Sanz M. L., Martínez-Castro I., Derivatization of carbohydrates for GC and GC-MS analyses. Journal of Chromatography B. 879(17), 1226-1240 (2011). DOI: 10.1016/j.jchromb.2010.11.013

15 Stoop J., Pharr D. M., Mannitol Metabolism in Celery Stressed by Excess Macronutrients. Plant Physiology, 106(2), 9503-9511 (1994). DOI: $10.1104 / p p .106 .2 .503$

16 Szarka A., Horemans N., Passarella S., Tarcsay Á., Örsi F., Salgó A., Bánhegyi G., Demonstration of an intramitochondrial invertase activity and the corresponding sugar transporters of the inner mitochondrial membrane in Jerusalem artichoke (Helianthus tuberosus L.) tubers. Planta, 228(5), 765-775 (2008). DOI: $10.1007 / \mathrm{s} 00425-008-0778-1$

17 Tolstikov V. V., Fiehn O., Analysis of Highly Polar Compounds of Plant Origin: Combination of Hydrophilic Interaction Chromatography and Electrospray Ion Trap Mass Spectrometry. Analytical Biochemistry, 301(2), 298-307 (2002).

DOI: $10.1006 /$ abio.2001.5513

18 Tomasskovics B., Szarka A., Comparison of mannitol and xylitol as osmolytes in preparation of mitochondria. in 'International Federation for Medical and Biological Engineering Proceedings' (ed.: Jobbágy Á.) Springer, Berlin/Heidelberg, Vol 351, 1362-1365 (2012). DOI: 10.1007/978-3-642-23508-5_351

19 Waldi D., Dünnschicht-Chromatographie einiger Zucker und Zuckeralkohole (Thin-layer chromatography of various sugars and sugar alcohols). Journal of Chromatography, 18, 417-418 (1965). DOI: 10.1016/S0021-9673(01)80390-3

20 Werhahn W., Niemeyer A., Jänsch L., Kruft V., Schmitz U. K., Braun H.-P., Purification and characterization of the preprotein translocase of the outer mitochondrial membrane from Arabidopsis. Identification of multiple forms of TOM20. Plant Physiology, 125(2), 943-954 (2001).

DOI: $10.1104 /$ pp.125.2.943 